\title{
Pemberdayaan Masyarakat Melalui Pendidikan Anak Usia Dini Di TK Labschool IKIP PGRI Jember
}

\author{
Eky Prasetya Pertiwi, S.Sos., M.Si ${ }^{1)}$, Hendrik Siswono, M.Pd ${ }^{2)}$ \\ ${ }^{1,2)}$ Institut Keguruan dan Ilmu Pendidikan PGRI Jember \\ eky.prasetya.pertiwi@gmail.com
}

\begin{abstract}
ABSTRAK: Pemberdayaan masyarakat pada lembaga anak usia dini merupakan implementasi dari pendidik, peserta didik, orang tua/wali, masyarakat lingkungan pendidikan. Untuk mewujudkan lingkungan yang aman, rapi tertib, kondusif dan merangsang anak untuk tertarik beraktivitas maka diperlukan kerjasama yang saling mendukung antara guru, orang tua dan masyarakat. Hal ini, pengabdi menerapkan pemberdayaan dalam sekolah TK Labschool IKIP PGRI Jember dengan melibatkan orang tua siswa dalam kegiatan peringatan Hari Kartini. Kegiatan dilakukan lomba-lomba yang melibatkan kerjasama dan interaksi orang tua dan siswa antara lain, peragaan busana daerah, pembuatan dan menghias celengan, dan melukis gypsum bersama. Kegiatan ini dilaksanakan di TK Labschool IKIP PGRI Jember Kecamatan Sumbersari Kabupaten Jember pada Tanggal 15 April 2019. Hasil pemberdayaan menjadikan orang tua terlibat secara langsung dalam acara yang telah diadakan oleh sekolah. Terbukti dengan keaktifan orang tua dalam membantu membuat dan menghias celengan serta membantu melukis gypsum. Selain itu, orang tua tidak memaksakan kehendaknya sendiri. Terbukti pada saat anak dan orang tua menghias celengan, orang tua lebih menuruti model seperti apa yang diinginkan anak. Program pendidikan anak usia dini haruslah menjadi pemenuhan berbagai macam kebutuhan anak, mulai dari kesehatan, nutrisi dan stimulasi pendidikan, juga harus dapat memberdayakan lingkungan masyarakat dimana anak mengalami perkembangan secara alami.

Kata kunci : Pemberdayaan Masyarakat, PAUD, Interaksi Sosial,
\end{abstract}

ABSTRACT: Community empowerment in early childhood institutions is an implementation of educators, students, parents / guardians, community education environment. To create a safe, orderly, conducive and stimulating environment for children to be interested in activities, it is necessary to have mutual support between teachers, parents and the community. This, the servants implemented empowerment in the Labschool Kindergarten IKIP PGRI Jember school by involving parents of students in the Kartini Day commemoration activities. Activities carried out competitions that involve collaboration and interaction between parents and students, among others, regional fashion shows, making and decorating piggy banks, and painting gypsum together. This activity was carried out at the Labschool Kindergarten IKIP PGRI Jember, Sumbersari District, Jember Regency on April 15, 2019. The results of the empowerment made parents directly involved in the events held by the school. Evidenced by the activeness of parents in helping to make and decorate piggy banks and help paint gypsum. In addition, parents do not impose their own will. Proven when the child and parents decorate the piggy bank, parents are more obedient to the model as what the child wants. Early childhood education programs must be a fulfillment of a variety of children's needs, ranging from health, nutrition and educational stimulation, must also be able to empower the community environment where children experience development naturally.

Keywords: Community Empowerment, Early Childhood Education, Social Interaction. 


\section{PENDAHULUAN}

Makna pendidikan tidaklah semata-mata dapat menyekolahkan anak di sekolah untuk menimba ilmu pengetahuan, namun lebih luas dari itu. Anak akan tumbuh dan berkembang dengan baik jika memperoleh pendidikan yang komprehensif agar kelak menjadi manusia yang berguna bagi Agama, Masyarakat, Bangsa dan Negara. Pendidikan hendaknya dilakukan sejak dini yang dapat dilakukan didalam keluarga, sekolah maupun masyarakat.

Pendidikan merupakan usaha sadar dengan sengaja dan terencana untuk membantu anak mengembangkan potensinya secara optimal sehingga ia mampu beradaptasi dengan lingkungannya. Pengertian tersebut mengandung makna bahwa esensi yang hakiki dari tujuan akhir pendidikan adalah kemampuan anak melakukan adaptasi dengan lingkungan yang luas. Dengan demikian tujuan pendidikan seharusnya menjadi dasar bagi proses pendidikan pembelajaran yaitu mendekatkan anak dengan lingkungannya. Pendidikan lingkungan pada anak usia dini sangatlah penting untuk dipahami oleh orang dewasa, terutama oleh orang tua dan masyarakat pada umumnya (Fasli, 2001).

Lingkungan hendaklah menjadi bagian yang kita pelajari dan kita kenali dengan baik. Jika kita abaikan atau tidak menjadi perhatian kita, maka pengaruhnya menjadi sangat sulit diramalkan terhadap anak, khususnya anak usia dini. Artinya jika kita berhasil memaknai lingkungan untuk pengembangan anak maka, kita akan mampu membantu tumbuh kembang anak secara baik. Sebaliknya jika gagal maka lingkungan itulah yang akan merusak anak, setidaknya menghambat atau mengganggu perjalanan tumbuh kembang anak. Untuk mewujudkan lingkungan yang aman, rapi tertib, kondusif dan merangsang anak untuk tertarik beraktivitas maka diperlukan kerjasama yang saling mendukung antara guru, orang tua dan masyarakat (Mariyana, 2005).

Proses pemberdayaan di dalam bidang pendidikan (termasuk PAUD) tidak bisa melalui pendekatan yang partial akan tetapi memerlukan pendekatan secara holistic yang meliputi pemberdayaan sumberdaya manusia (termasuk didalamnya pendidik, peserta didik, orang tua/wali, masyarakat lingkungan pendidikan,sponsor/pemerintah, dan pengguna lulusan), sistem pembelajaran, manajemen kelembagaan pendidikan dengan segala sarana dan rasaran pendukungnya, sumberdaya alam, sumberdaya teknologi, dan lain sebagainya (Heryanto, 2009)

TK Labschool IKIP PGRI Jember merupakan salah satu lembaga sekolah anak usia dini yang terletak di kampus IKIP PGRI Jember. Penerimaan siswa TK dimulai dari umur 2-6 tahun dengan kelompok-kelompok kelas tertentu. Kegiatan rutin untuk siswa TK Labscchool IKIP PGRI Jember di setiap tahun nya sudah banyak dilakukan sebagai bentuk pembelajaran yang dilakukan oleh lembaga. Akan tetapi, kegiatan yang muncul hanya melibatkan siswa saja, dan jarang untuk melibatkan wali murid sehingga interaksi lembaga dengan komite wali murid masih tergolong kurang. Kurang interaksi ini maka diadakan kegiatan pemberdayaan masyarakat terutama wali murid TK Labschool IKIP 
PGRI Jember agar dapat menjadi pembelajaran lingkungan yang membantu anak untuk melakukan adaptasi dengan lingkungan yang luas.

\section{PERMASALAHAN}

Berdasarkan hasil Focus Group Discussion (FGD) yang dilakukan tim pelaksana kegiatan pengabdian pemberdayaan dengan 6 orang guru TK Labschool IKIP PGRI Jember, diperoleh data permasalahan yaitu. 1) masyarakat belum seluruhnya aktif mengikutsertakan anaknya mengikuti kegiatan TK. Kalaupun telah terdaftar belum seluruhnya aktif mengantar anaknya sesuai jadwal hari kegiatan TK. Ketika orangtua sedang mempunyai kesibukan, anak tidak diantar ke sekolah. 2) Partisipasi masyarakat terutama wali murid untuk terlibat dalam pembelajaran masih rendah. Hal ini dikarenakan pekerjaan wali murid TK yang banyak bekerja sebagai PNS, Karyawan, pengusaha, dll sehingga waktu partsisipasi tidak memungkinkan.

Permasalahan tersebut oleh tim pengabdi dijadikan pemberdayaan yang dapat membuat wali murid berpartisipasi seluruhnya sebagai pendamping anak-anak yaitu pada peringatan hari Kartini pada tanggal 15 April 2019 dengan berbagai kegiatan siswa dengan didampingi oleh masing-masing orang tua siswa. Hal ini diharapkan dapat meningkatkan interaksi wali murid sebagai orang tua siswa dengan anak sebagai siswa dalam pembelajaran untuk membantu anak mengembangkan potensinya secara optimal sehingga ia mampu beradaptasi dengan lingkungannya.

\section{METODE PELAKSANAAN}

Solusi permasalahan ini dilakukan kegiatan yang melibatkan orang tua siswa dengan siswa dalam pendampingan kegaiatan di peringatan Hari Kartini. Rencana kegiatan pengabdian akan dilakukan lomba-lomba yang melibatkan kerjasama dan interaksi orang tua dan siswa antara lain, peragaan busana daerah, pembuatan dan menghias celengan, dan melukis gypsum bersama. Kegiatan ini dilaksanakan di TK Labschool IKIP PGRI Jember Kecamatan Sumbersari Kabupaten Jember pada Tanggal 15 April 2019 dengan perencanaan program kegiatan dilakukan di awal bulan April.

Prosedur kegiatan dilakukan dengan awal Focus Group Discussion (FGD) pada awal bulan April bersama Guru TK dan beberapa pelibatan mahasiswa Program studi PG.PAUD - FIP IKIP PGRI Jember yang dihasilkan pembentukan panitia kecil dan rencana kegiatan dalam peringatan Hari Kartini. Setelah itu, mempersiapkan alat dan bahan yang akan dipakai ketika kegaiatan berlangsung, sebagai contoh Gypsum untuk dilukis, background pentas, dan lainnya. Pada waktu kegiatan berlangsung, seluruh tim bertugas sesuai pembagian masing-masing dan bekerjasama dengan guru TK. Data yang diambil adalah data wawancara kepala sekolah TK dan dokumentasi kegiatan peringatan Hari Kartini April 2019. 


\section{PELAKSANAAN}

Kegiatan Pengabdian Pada Masyarakat dengan sasaran orang tua siswa dan siswa TK Labschool IKIP PGRI Jember dilaksanakan selama satu bulan yaitu bulan April yang diikuti oleh siswa TK sebanyak 60 siswa bersama orang tua siswa. Pelaksanaan melibatkan pengabdi, guru TK, dan mahasiswa Program Studi PG.PAUD IKIP PGRI Jember.

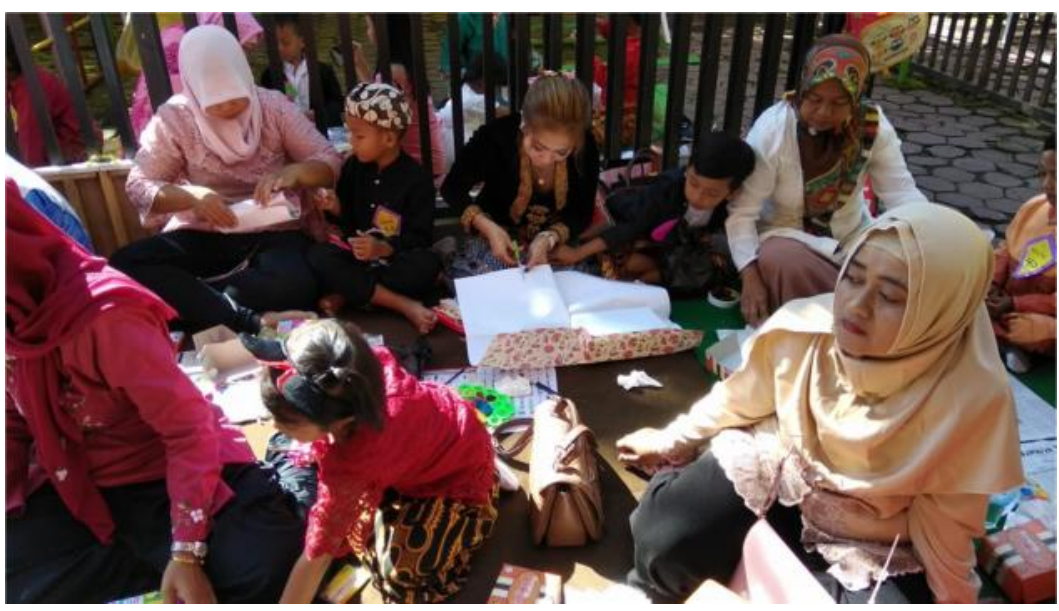

Gambar 1. Membuat dan menghias celengan

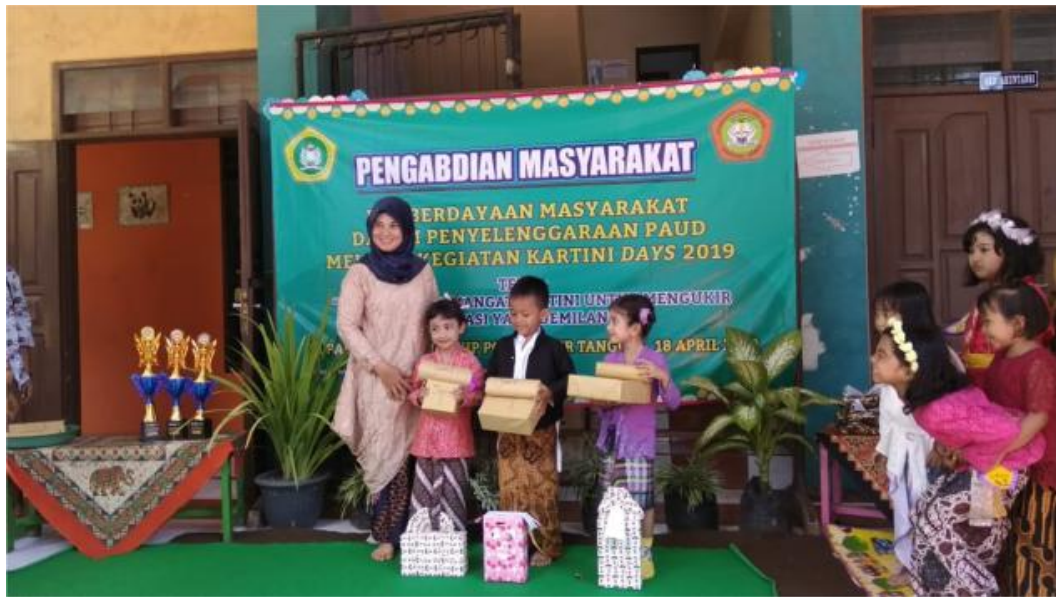

Gambar 2. Kejuaran menmbuat dan menghias celengan 


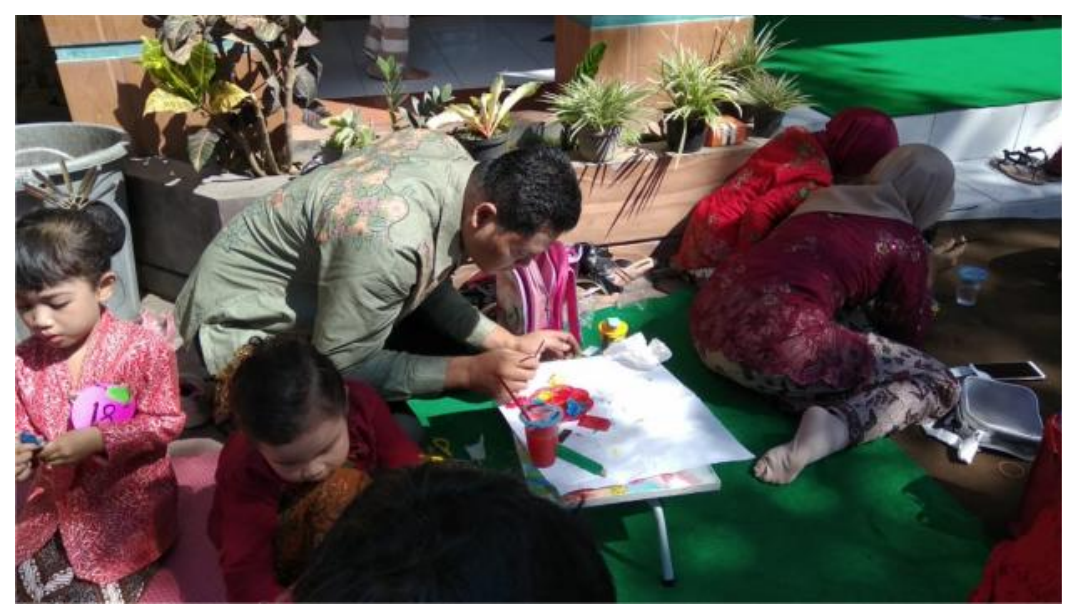

Gambar 3. Melukis Gypsum

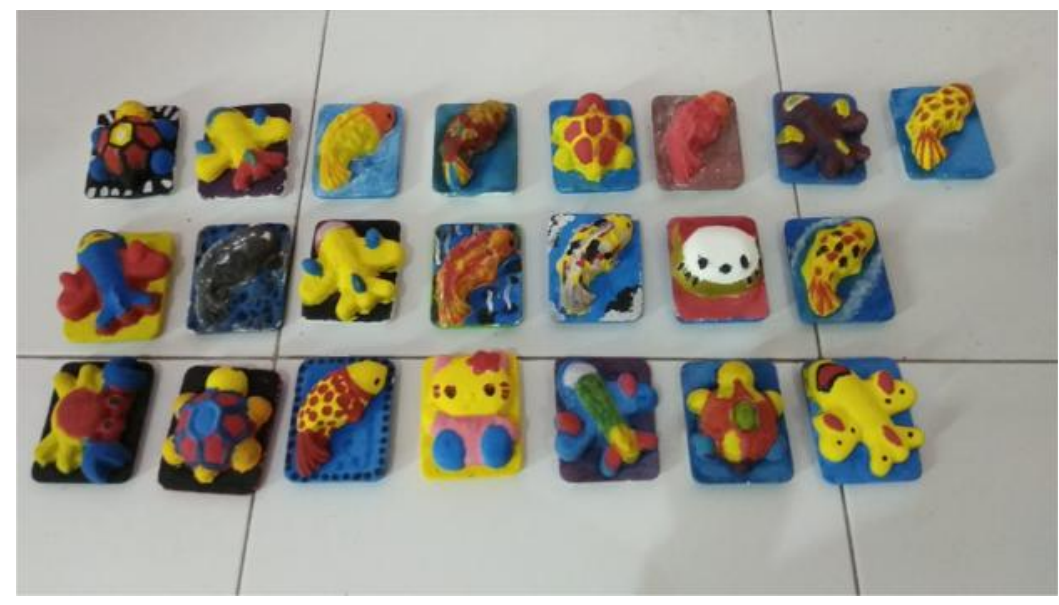

Gambar 4. Hasil karya melukis Gypsum

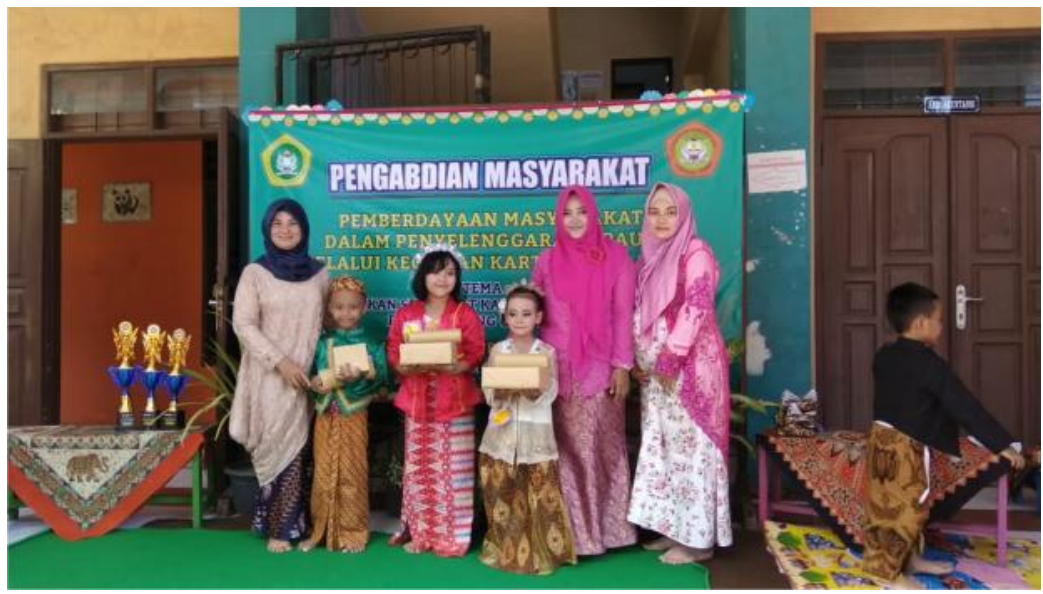

Gambar 5. Kejuaraan melukis Gypsum 


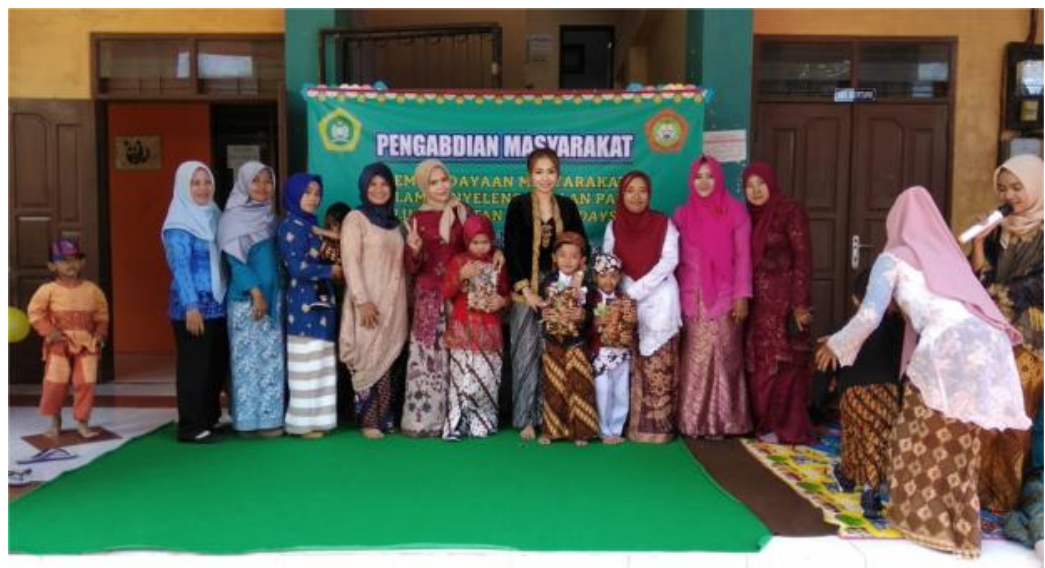

Gambar 6. Kejuaraan peragaan busana

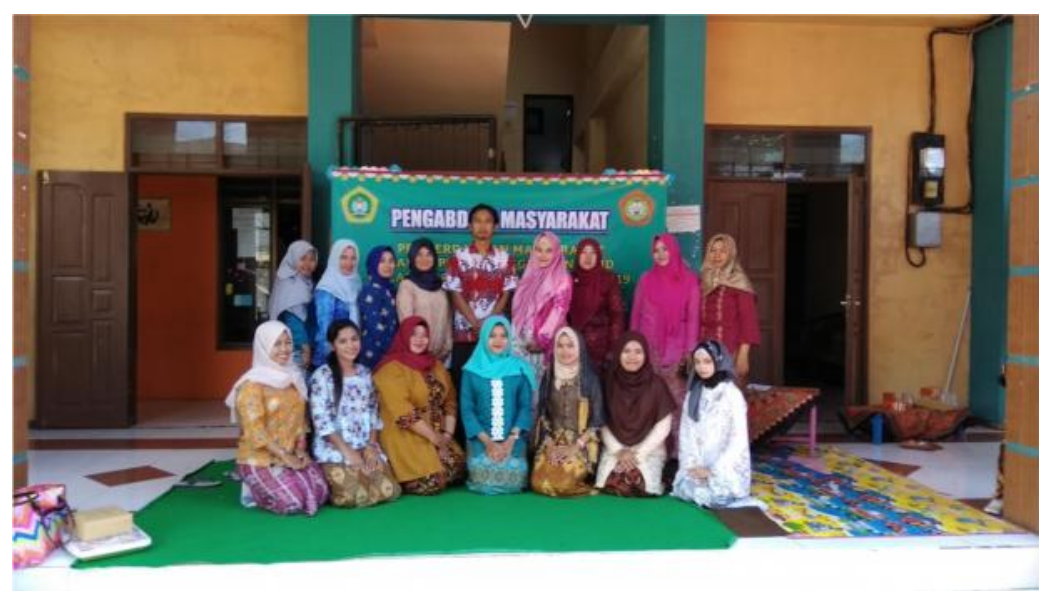

Gambar 7. Foto pengabdi, guru, dan mahasiswa

\section{HASIL DAN LUARAN}

Hasil pelaksanaan pengabdian pemberdayaan masyarakat adalah meningkatkan interaksi siswa dengan orang tua, menumbuhkan rasa hubungan secara emosional antara siswa dengan orang tua, dan menumbuhkan rasa percaya diri seorang anak bersama orang tuanya. Perkembangan sosial tidak terlepas peran dari faktor-faktor keluarga karena rumah pertama bagi anak adalah keluarga, relasi anak dengan teman sebayanya, dan kualitas bermain yang dilakukan bersama teman sebayanya. Relasi awal dengan orang tua merupakan pondasi dicapainya kompetensi sosial dan hubungan dengan teman sebayanya. Jika dirumah anak kurang berinteraksi dengan anggota keluarga kemungkinan terjadi diluar rumah anak sulit untuk berinteraksi dengan teman sebayanya (Soetjiningsih, 2012).

Luaran yang diperoleh adalah orang tua semakin memahami perkembangan anak secara kontekstual di sekolah, dan diadakannya kegiatan rutin setiap satu bulan bersama orang tua siswa untuk berkunjung ke rumah teman secara bergiliran. 


\section{KESIMPULAN}

Pemberdayaan yang dapat membuat wali murid berpartisipasi seluruhnya sebagai pendamping anak-anak yaitu pada peringatan hari Kartini pada tanggal 21 April 2019 dengan berbagai kegiatan siswa dengan didampingi oleh masing-masing orang tua siswa. Hal ini menjadikan Orang tua terlibat secara langsung dalam acara yang telah diadakan oleh sekolah. Terbukti dengan keaktifan orang tua dalam membantu membuat dan menghias celengan serta membantu melukis gypsum. Selain itu, orang tua tidak memaksakan kehendaknya sendiri. Terbukti pada saat anak dan orang tua menghias celengan, orang tua lebih menuruti model seperti apa yang diinginkan anak. Begitu juga pada saat melukis gypsum, orang tua hanya memberi arahan warna tanpa diharuskan menuruti kemauan orang tua.

Pemberdayaan masyarakat khususnya orang tua siswa TK Labschool IKIP PGRI Jember yang berlokasi di Kampus IKIP PGRI Jember telah dijalankan dengan baik dan tanpa halangan yang berarti. Interaksi orang tua yang jarang ditemui dalam pembelajaran, kini mulai tercipta dengan adanya kegiatan rutin tiap bulan yang dilakukan oleh orang tua siswa bersama siswa dalam kunjungan ke rumah teman.

Perkembangan fisik dan mental anak berkembang secara maksimal, peran sekolah, keluarga, dan masyarakat adalah untuk mendudukung perkembangan anak dengan menyediakan dan mengkondisikan waktu, kesempatan, dan sumber daya yang dibutuhkan untuk perkembangan fisik dan mental anak. Program pendidikan anak usia dini haruslah menjadi pemenuhan berbagai macam kebutuhan anak, mulai dari kesehatan, nutrisi dan stimulasi pendidikan, juga harus dapat memberdayakan lingkungan masyarakat dimana anak mengalami perkembangan secara alami.

\section{DAFTAR PUSTAKA}

Fasli, D. 2001. Pendidikan Anak Usia Dini. Jakarta : Departemen Pendidikan Nasional.

Heryanto, N. 2009. Pemberdayaan Masyarakat Dalam PAUD Nonformal. Jurnal Pendidikan Luar Sekolah. Vol 4 (2). UPI.

Mariyana, R. 2005. Strategi Pengelolaan Lingkungan Belajar. Jakarta: Departemen Pendidikan Nasional.

Soetjiningsih, C. 2012. Perkembangan Anak. Jakarta : Prenada. 
Volume 4, Nomor 1, Maret 2020 